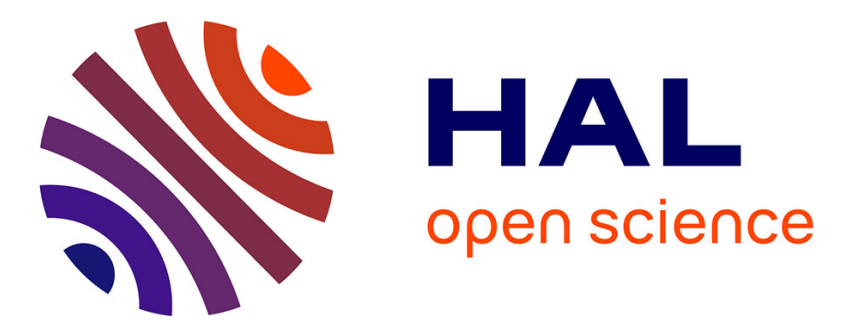

\title{
A shakedown analysis of high cycle fatigue of shape memory alloys
}

\author{
F. Auricchio, A. Constantinescu, C. Menna, G. Scalet
}

\section{To cite this version:}

F. Auricchio, A. Constantinescu, C. Menna, G. Scalet. A shakedown analysis of high cycle fatigue of shape memory alloys. International Journal of Fatigue, 2016, 87, pp.112-123. 10.1016/j.ijfatigue.2016.01.017 . hal-01282081

\section{HAL Id: hal-01282081 \\ https://hal-polytechnique.archives-ouvertes.fr/hal-01282081}

Submitted on 3 Feb 2021

HAL is a multi-disciplinary open access archive for the deposit and dissemination of scientific research documents, whether they are published or not. The documents may come from teaching and research institutions in France or abroad, or from public or private research centers.
L'archive ouverte pluridisciplinaire HAL, est destinée au dépôt et à la diffusion de documents scientifiques de niveau recherche, publiés ou non, émanant des établissements d'enseignement et de recherche français ou étrangers, des laboratoires publics ou privés.

\section{(c)(1)}

Distributed under a Creative Commons Attribution| 4.0 International License 
This is the pre-peer reviewed version of the following article:

F. Auricchio, A. Constantinescu, C. Menna, G. Scalet. A shakedown analysis of high cycle fatigue of shape memory alloys, International Journal of Fatigue, 87: 112-123, 2016

which has been published in final form at https://doi.org/10.1016/j.ijfatigue.2016.01.017 


\title{
A shakedown analysis of high cycle fatigue of shape memory alloys
}

\author{
F. Auricchio ${ }^{\mathrm{a}}$, A. Constantinescu ${ }^{\mathrm{b}}$, C. Menna ${ }^{\mathrm{c}}$, G. Scalet ${ }^{\mathrm{a}, \mathrm{b}, *}$ \\ ${ }^{a}$ Dipartimento di Ingegneria Civile e Architettura, Università di Pavia, \\ Via Ferrata 3, 27100 Pavia, Italy \\ ${ }^{b}$ Laboratoire de Mécanique des Solides - CNRS UMR 7649, École Polytechnique, \\ 91128 Palaiseau cedex, France \\ c Dipartimento di Strutture per l'Ingegneria e l'Architettura, Università di Napoli 'Federico II', \\ Via Claudio 21, 80125 Napoli, Italy
}

\begin{abstract}
Shape memory alloys (SMAs) are exploited in several innovative applications, experiencing up to millions of cycles, and thus requiring a fully understanding of material fatigue and fracture resistance. However, experimental and methodological descriptions of SMA cyclic response are still incomplete. Accordingly, the present paper aims to investigate the cyclic response of SMAs under macroscopic elastic shakedown and to propose a criterion for the high cycle fatigue of SMAs. A multiaxial criterion based on a multiscale analysis of the phase transformation between austenite and martensite and using the rigorous framework of standard generalized materials is proposed. The criterion is an extension of the Dang Van high cycle fatigue criterion to SMAs. The criterion is applied to uniaxial experimental data taken from the literature. It distinguishes run out from failure tests in the infinite lifetime regime. The sound structure of the underlying concepts permits a novel insight into the development of a general multiaxial failure criterion for SMA materials.

Keywords: Shape memory alloys, Lifetime prediction, Dang Van fatigue criterion, Shakedown, High cycle fatigue

*Corresponding author. Laboratoire de Mécanique des Solides - CNRS UMR 7649, École Polytechnique, 91128 Palaiseau cedex, France

Tel.: +33169335712 .

Email address: giulia.scalet@unipv.it (G. Scalet)
\end{abstract}




\section{INTRODUCTION}

Shape memory alloys (SMAs) possess unique properties, known as shape memory effect and pseudoelasticity. These properties result from reversible diffusionless solid-solid transformations (known as martensitic transformations) between a relatively ordered parent phase, called austenite (A), and a less ordered product phase, called martensite $(\mathrm{M})$.

Shape memory effect and pseudoelasticity are successfully exploited in many fields, e.g., structural engineering, automotive, aerospace, micro-electromechanical, robotics, and biomedical industry (Jani et al., 2014; Lagoudas, 2008). In particular, a wide segment is covered by SMA actuation systems (Mertmann and Vergani, 2008) and by innovative devices for the control of civil structures (Asgarian and Moradi, 2011). Within the biomedical industry, self-expandable vascular stents represent a considerable part of SMA applications for mini-invasive techniques (Petrini and Migliavacca, 2011). The question of lifetime prediction and of the improvement of the alloys with respect to this aspect is a major topic in the field (Chluba et al., 2015; James, 2015).

The rather complex micromechanical behaviour of SMAs also induces unusual fracture and fatigue responses when compared with polycrystalline metallic alloys (Mahtabi et al., 2015; Robertson et al., 2012). It has already been discussed, for instance by Tabanli et al. $(1999,2001)$, that classical fatigue criteria cannot be directly applied, due to the uncertain role of the phase transformation under cyclically varying deformations and of the stress and/or thermally-induced microstructural evolution of the different phases (Robertson et al., 2012). Indeed, transformations between austenitic and martensitic phases, moving martensite interfaces, accumulation of dislocations are believed to play an important role in the fatigue lifetime of SMAs (Barney et al., 2011; Pelton, 2011).

The prediction of crack initiation and growth under thermo-mechanical cyclic loading is an essential requirement for the design of novel SMA components (Rahim et al., 2013), since fatigue failure has emerged as one of the main design issues (Azaouzi et al., 2013; Hibbert and O'Brien, 2011). As an example, SMA actuators are subjected to thermal cycling and are expected to undergo at least $10^{4}-10^{5}$ cycles during their 
service life (Karhu and Lindroos, 2010; Strittmatter and Gümpel, 2011). For SMA cables used as damping prevention in stay cable, suspension, and prestressed concrete bridges, fatigue life is usually taken into account considering the frequency range of vibration on real scale bridges, i.e. $5-20 \mathrm{~Hz}$, and a number of working cycles up to $5 \cdot 10^{6}$ (Menna et al., 2015). In the majority of the biomedical applications, stents are permanently implanted in the human body and experience millions of in-vivo cycles due to blood pressure; stents should survive at least for 10 years without exhibiting failure, which translates into $4 \cdot 10^{8}$ service cycles (US Food and Drug Administration, 2010).

In order to prevent premature failure of SMA components, it is firstly necessary to verify whether they will shakedown elastically or by alternating phase transformation, or will fail by alternating plasticity. The shakedown regions in a typical fatigue diagram are usually associated with high and low cycle fatigue regime (Constantinescu et al., 2003). Figures 1(a) and (b) show two possible cases of SMA uniaxial pseudoelastic response under cyclic loading, i.e. under alternating phase transformation and elastic shakedown, respectively.

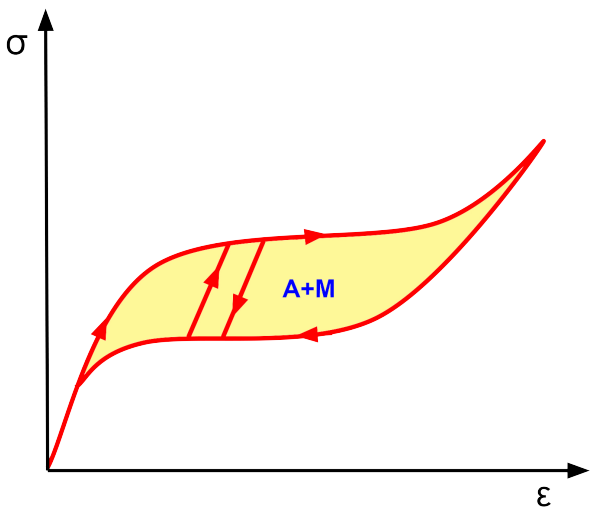

(a)

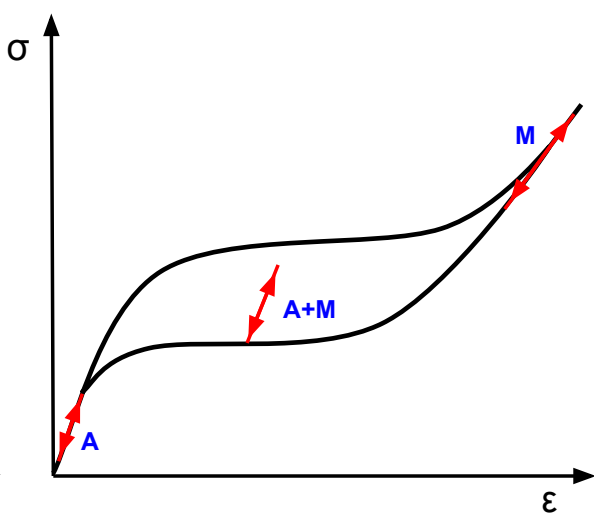

(b)

Figure 1: Two examples of SMA pseudoelastic response under cyclic loading with strain-stress paths denoted by red lines: (a) alternating phase transformation; (b) elastic shakedown.

Several experimental investigations and fatigue methodologies have analyzed both SMA structural fatigue (component failure) and functional fatigue (the evolution of 
shape memory effect and pseudoelasticity under repeated thermo-mechanical cycles); see Robertson et al. (2012) as review article.

Experimental investigations are generally coupled with observations to track the nucleation and evolution of martensite and austenite during mechanically unstable regimes with the final aim of characterizing the material fatigue response on a microscopic and even macroscopic level (Brinson et al., 2004; Creuziger et al., 2008; Gall et al., 2008; Gloanec et al., 2010; Kim and Daly, 2011; Lackmann et al., 2011; Merzouki et al., 2010; Pelton, 2011; Treadway et al., 2015; Yin et al., 2014). Experimental observations have also inspired a series of fatigue approaches aimed to estimate the lifetime, as a macroscopic crack initiation criterion. Most of the studies focus on stress- or strain-life SMA fatigue approaches for different types of uniaxial tensile loading, e.g., (Gupta et al., 2014; Kang et al., 2012; Maletta et al., 2012; Pelton et al., 2013; Wang et al., 2008), while only few focus on the torsional fatigue loading of SMAs, e.g., (Predki et al., 2006; Runciman et al., 2011).

Concerning available failure criteria, although uniaxial ones may fail to accurately predict the lifetime of devices under multiaxial loading conditions, only few multiaxial fatigue criteria exist for SMAs. It is worth mentioning the works by Moumni et al. (2005, 2009) and Morin et al. (2010) who firstly proposed an energy approach, where the dissipated energy of the pseudoelastic hysteresis cycle was used as a parameter for lifetime estimation. Recently, Hartl et al. (2014) proposed a constitutive model describing SMA behaviour undergoing a large number of cycles, coupled with a continuum theory which includes an internal damage evolving into final failure. These approaches focus on the cyclic alternating phase transformation behaviour of SMAs. Only few works have been proposed to extend the shakedown theorems for elasto-plastic materials to SMA structures, see, e.g., (Feng and Sun, 2007; Peigney, 2010, 2013, 2014; Pham, 2008; Wu et al., 1999). To the authors' knowledge, no works address the fatigue analysis of SMA elastic shakedown, even though such a loading condition is very frequent in various applications (Robertson et al., 2012).

Motivated by the above considerations, the present paper focuses on the cyclic response of SMAs, under the elastic shakedown regime, and proposes a multiaxial criterion for the high cycle fatigue of SMAs. The derivation starts from the following 
considerations: such criterion should (i) predict high cycle fatigue crack initiation; (ii) be based on a multiscale analysis taking into account the complexity of the phase transformation between austenite and martensite; (iii) be multiaxial.

The Dang Van-Papadopoulos criteria (Dang Van et al., 1989; Papadopoulos, 1987) belong to the class of fatigue criteria fulfilling the above conditions. Their merit comes from the underlying fundamental concepts of shakedown and standard generalized materials applied at the grain level in metallic polycrystals. Such criteria have have been successfully applied to both infinite and finite lifetime in the high cycle fatigue regime (Ferjani et al., 2011a; Papadopoulos, 2001; Van and Maitournam, 2002; Wackers et al., 2010b). The homogenization assumptions relating the grain scale plasticity with the macroscopic behavior have been discussed in (Bertolino et al., 2007; Hofmann et al., 2009). They have permitted to extend consistently the criterion to finite lifetime (Bosia and Constantinescu, 2012; Morel, 2000a) as well as to explain the scatter of fatigue experiments and to explore the effect of loading path (Guerchais et al., 2014) to include the presence of stress concentrations created by defects (Guerchais et al., 2014). Moreover, the coherent thermodynamic foundation permitted to relate plastic dissipation with self-heating (Charkaluk and Constantinescu, 2009; Luong, 1998) and it opened innovative techniques for lifetime predictions (Doudard et al., 2004, 2007; Poncelet et al., 2010).

The aim of this paper is to derive a similar thermodynamically consistent framework for the analysis of fatigue in polycrystalline SMAs. Generally, polycrystalline SMAs present a complex microstructure made of austenite and/or martensite, which appear in the form of plates, inclusions, or grains. Therefore, three different length scales can be considered, corresponding to different systems: (i) the microscopic scale of microstructures (pellets, inclusions, bands, etc.) formed in each grain; (ii) the mesoscopic scale of individual grains; and (iii) the macroscopic scale of the polycrystalline material, consisting in several grains (Peigney, 2009). Here, we consider classical homogenization assumptions to evaluate the mesoscopic mechanical quantities from the macroscopic ones and we perform the shakedown analysis by using the recent theorems by Peigney $(2010,2013,2014)$, obtained for a large class of SMA constitutive laws within the generalized standard materials framework. 
The shakedown and multiscale analysis is then applied to a series of uniaxial fatigue experiments taken from literature (Pelton, 2011). A constitutive law of the SouzaAuricchio type (Auricchio and Petrini, 2004; Souza et al., 1998a,b) is identified on the specific material and the complete mechanical behaviour is computed for all the test cases. The proposed fatigue criterion successfully predicts failure or run out of the tested specimens.

The analysis leads to a new insight in the analysis of the fatigue phenomena in SMA materials and it opens a new path for the development of a general multiaxial failure criterion for this class of materials and the manufacturing of new alloys.

The present paper is organized as follows. Section 2 presents a review of the thermodynamic framework of the constitutive laws and the shakedown theorems for SMAs. Then, Section 3 introduces the Dang Van type criterion for SMAs. Section 4 presents the results of its application to experiments from the literature. Conclusions and summary are finally given in Section 5. A scheme of the numerical algorithm for the computation of the fatigue criterion is provided in Appendix A.

\section{THERMODYNAMIC FRAMEWORK AND SHAKEDOWN THEOREM FOR SMAs}

This section reviews the constitutive laws and the shakedown theorem for SMAs in the framework of generalized standard materials (Halphen and Nguyen, 1975).

\subsection{Thermodynamic framework}

Assuming a small strain regime, the initial configuration of the local SMA material state is described by the total strain $\boldsymbol{\varepsilon}$, the temperature $\theta$, and an internal variable $\boldsymbol{\alpha}$. The variable $\boldsymbol{\alpha}$ represents the inelastic strain and can include the description of several physical phenomena characterizing SMA behaviour, ranging from permanent plasticity and phase transformations, up to void generation and fracture (Peigney, 2010).

According to (Halphen and Nguyen, 1975), the constitutive model is defined in terms of the free energy $w$ and the pseudo-potential of dissipation $\phi$, from which the stress tensor $\boldsymbol{\sigma}$ and the thermodynamic force $\mathbf{A}$ associated to $\boldsymbol{\alpha}$ are derived. 
The free energy is assumed to depend on the total strain $\boldsymbol{\varepsilon}$, the temperature $\theta$, and the internal variable $\boldsymbol{\alpha}$, i.e., $w=w(\boldsymbol{\varepsilon}, \theta, \boldsymbol{\alpha})$, as follows:

$$
w=\frac{1}{2}(\boldsymbol{\varepsilon}-\boldsymbol{\alpha}): \mathbb{C}:(\boldsymbol{\varepsilon}-\boldsymbol{\alpha})+f
$$

where $f=f(\theta, \boldsymbol{\alpha})$ is a positive differentiable function, describing the energy contribution associated to the internal variable and temperature variations. Here and in the following, the stiffness tensor $\mathbb{C}$ is assumed to depend on the component of the internal variable describing phase transformation.

The free energy describes the relation between the state and internal variables $\boldsymbol{\varepsilon}$ and $\boldsymbol{\alpha}$ and their conjugate quantities $\boldsymbol{\sigma}$ and $\mathbf{A}$, as follows:

$$
\left\{\begin{array}{l}
\boldsymbol{\sigma}=\frac{\partial w}{\partial \boldsymbol{\varepsilon}}=\mathbb{C}:(\boldsymbol{\varepsilon}-\boldsymbol{\alpha}) \\
\mathbf{A}=-\frac{\partial w}{\partial \boldsymbol{\alpha}}=\boldsymbol{\sigma}-\frac{1}{2}(\boldsymbol{\varepsilon}-\boldsymbol{\alpha}): \frac{d \mathbb{C}}{d \boldsymbol{\alpha}}:(\boldsymbol{\varepsilon}-\boldsymbol{\alpha})-\frac{\partial f}{\partial \boldsymbol{\alpha}}
\end{array}\right.
$$

The evolution of the internal variable $\boldsymbol{\alpha}$ is described in terms of the time derivative $\dot{\boldsymbol{\alpha}}$ by using the pseudo-potential of dissipation $\phi=\phi(\dot{\boldsymbol{\alpha}})$, which is a positive convex functional vanishing at the origin.

It is then convenient to introduce the complementary pseudo-potential of dissipation $\phi^{*}=\phi^{*}(\mathbf{A})$, which is the Legendre-Fenchel transform of $\phi$. Such a step requires the introduction of the indicator function $I_{\mathcal{P}}(\mathbf{A})$ :

$$
\phi^{*}=I_{\mathcal{P}}(\mathbf{A})= \begin{cases}0 & \text { if } \mathbf{A} \in \mathcal{P} \\ +\infty & \text { otherwise }\end{cases}
$$

where $\mathcal{P}=\{\mathbf{A} \mid F(\mathbf{A}) \leq 0\}$ is the set of admissible thermodynamic forces, described in terms of the limit function $F$. In classical plasticity $F$ represents the yield limit, while it describes phase transformation and/or permanent plasticity in the case of SMAs.

The evolution equation for $\boldsymbol{\alpha}$ in terms of $\phi^{*}$ is derived as (Frémond, 2002; Peigney, 2010):

$$
\dot{\boldsymbol{\alpha}} \in \partial \phi^{*}(\mathbf{A})=\partial I_{\mathcal{P}}(\mathbf{A})
$$


while the evolution equation for $\mathbf{A}$ in terms of $\phi$ is obtained as follows:

$$
\mathbf{A} \in \partial \phi(\dot{\boldsymbol{\alpha}})+\partial I_{\mathcal{T}}(\boldsymbol{\alpha})
$$

The internal variable $\boldsymbol{\alpha}$ is constrained to take values in a convex and closed subset $\mathcal{T}$, with the term $\partial I_{\mathcal{T}}(\boldsymbol{\alpha})$ representing the subdifferential of the indicator function $I_{\mathcal{T}}(\boldsymbol{\alpha})$, defined to enforce the constraint on $\boldsymbol{\alpha}$, as follows:

$$
I_{\mathcal{T}}(\boldsymbol{\alpha})= \begin{cases}0 & \text { if } \boldsymbol{\alpha} \in \mathcal{T} \\ +\infty & \text { otherwise }\end{cases}
$$

Then, the thermodynamic force $\mathbf{A}$ associated to $\boldsymbol{\alpha}$ is defined as follows:

$$
\left\{\begin{array}{l}
\mathbf{A}=\mathbf{A}^{d}+\mathbf{A}^{r} \\
\mathbf{A}^{d} \in \partial \phi(\dot{\boldsymbol{\alpha}}) \\
\mathbf{A}^{r} \in \partial I_{\mathcal{T}}(\boldsymbol{\alpha})
\end{array}\right.
$$

where $\mathbf{A}^{d}$ represents the dissipative force and $\mathbf{A}^{r}$ the non-dissipative force reacting to the internal constraint on $\boldsymbol{\alpha}$.

\subsection{Shakedown analysis}

In the reviewed modeling of the thermodynamic framework, the concept of shakedown is essential for systems undergoing a given cyclic loading history. Recently, Peigney (2010) has addressed the asymptotic behaviour of non-smooth mechanical systems and provided the necessary and sufficient conditions ensuring elastic shakedown. This was accomplished by bounding the mechanical dissipation, which is actually the extension of the original line of thought of (Koiter, 1960; Nguyen, 2003) to non-smooth mechanics. It is worth pointing out that shakedown theorems reported by Peigney (2010) are general and do apply to all SMA models entering the class of generalized standard materials. Within this family, we can cite the models proposed by Lagoudas et al. (2012); Leclercq and Lexcellent (1996); Moumni et al. (2008); Sedlák et al. (2012); Souza et al. (1998b); Stupkiewicz and Petryk (2012); Zaki and Moumni (2007). 
Let us consider a SMA structure under cyclic loading. Its response is described in terms of state and internal variables $(\boldsymbol{\varepsilon}, \theta, \boldsymbol{\alpha})$ and the conjugate quantities $(\boldsymbol{\sigma}, \mathbf{A})$. If the structure attains an elastic shakedown state at time $t>t_{0}$, then $\boldsymbol{\alpha}(t)$ and $\mathbf{A}(t)$ are constant, meaning that the response of the structure is elastic around a fixed residual stress field triggered by a fixed inelastic strain characterizing the phase transformation and/or permanent plasticity. It is therefore convenient to consider the elastic response of the structure, defined by the fictitious elastic stress hystory $\sigma^{e}$.

The theorem by Peigney (2010) establishes the following result:

Shakedown theorem. If there exists a positive coefficient $m>1$, a time $t_{0}$, and a time-independent field $\mathbf{A}_{*}^{r}$ such that

$$
F\left(m \boldsymbol{\sigma}^{e}(t)-\mathbf{A}_{*}^{r}\right) \leq 0 \text { for all } t>t_{0}
$$

then there is elastic shakedown, whatever the initial condition is.

Here, $\boldsymbol{\sigma}^{e}=\mathbb{C} \boldsymbol{\varepsilon}^{e}$ is the fictitious elastic response of the system and $\mathbf{A}_{*}^{r}$ the residual stress or eigenstress generated by the inelastic processes of phase transformation and/or irreversible plasticity.

The shakedown theorem actually states that the structure will attain a shakedown state under a given cyclic loading, provided that the fictitious elastic stress path can be included in the limit domain defined by the limit function $F$, translated by a residual stress field $\mathbf{A}_{*}^{r}$.

For the numerical computations of Section 4 we will employ, as SMA constitutive model, the three-dimensional phenomenological model originally presented by Souza et al. (1998a,b) and then investigated by Auricchio and Petrini (2004), and Auricchio et al. (2009b) (denoted in the following as the Souza-Auricchio model). The model assumes a deviatoric second-order tensor representing the transformation strain associated to transformations between austenite and martensite as internal variable, i.e. $\boldsymbol{\alpha}=\mathbf{e}^{t r}$. Such an internal variable is constrained to satisfied the inequality $\left\|\mathbf{e}^{t r}\right\| \leq \varepsilon_{L}$, where $\varepsilon_{L}$ is a parameter related to the maximum transformation strain reached at the end of the transformation during a uniaxial test. We further define the martensite volume fraction as $z=\left\|\mathbf{e}^{t r}\right\| / \varepsilon_{L}$. Indeed, $z$ varies between 0 (fully austenite) and 1 (fully 
martensite).

The free-energy and the dissipation pseudo-potentials are thus defined as:

$$
\left\{\begin{array}{l}
w=\frac{1}{2}\left(\boldsymbol{\varepsilon}-\mathbf{e}^{t r}\right): \mathbb{C}:\left(\boldsymbol{\varepsilon}-\mathbf{e}^{t r}\right)+\beta\left\langle\theta-\theta^{*}\right\rangle\left\|\mathbf{e}^{t r}\right\|+\frac{1}{2} h\left\|\mathbf{e}^{t r}\right\|^{2} \\
\phi=R\left\|\dot{\mathbf{e}}^{t r}\right\| \\
\phi^{*}=I_{\mathcal{P}}(\mathbf{A})
\end{array}\right.
$$

Here, $h$ is a positive parameter related to material hardening during phase transformation; $\beta$ a positive material parameter related to the dependence of the critical stress on temperature; $\theta^{*}$ the temperature below which only martensite phase is stable; the notation $\langle\cdot\rangle$ denotes the positive part function, while $\|\cdot\|$ denotes the Euclidean norm.

The set of admissible thermodynamic forces $\mathcal{P}=\{\mathbf{A} \mid F(\mathbf{A}) \leq 0\}$ is described in terms of the limit function $F$, taken in the form:

$$
F=\|\mathbf{A}\|-R
$$

with $R$ the positive radius of the elastic domain. Recall that the thermodynamic force $\mathbf{A}$ is the work-conjugate to the deviatoric transformation strain and it is thus indicated as deviatoric transformation stress.

For the Souza-Auricchio model, the shakedown theorem (see inequality (8)) becomes:

Shakedown theorem (Souza-Auricchio model). If there exists a positive coefficient $m>1$, a time $t_{0}$, and a time-independent field $\mathbf{A}_{*}^{r}$ such that

$$
\left\|m \mathbf{s}^{e}-\mathbf{A}_{*}^{r}\right\| \leq R \text { for all } t>t_{0}
$$

then there is elastic shakedown, whatever the initial condition is.

Here, $\mathbf{s}^{e}$ is the deviatoric part of $\boldsymbol{\sigma}^{e}$.

\section{FATIGUE CRITERION POSTULATION FOR SMA INFINITE LIFETIME}

\subsection{Macro-meso passage}

In high cycle fatigue, dissipation can be considered negligible and, therefore, it is accepted that only few grains of the SMA material undergo inelastic deformations 
whilst most of the material remains elastic. Hence, a multiscale analysis is applied to relate the macroscopic with the microscopic variables, i.e. between the scale of the structure and that of the material grains (Dang Van et al., 1989; Morel, 2000b; Papadopoulos, 2001); this situation is schematically represented in Figure 2 for SMAs. The material point at the macroscopic scale is considered as a representative elementary volume (REV) at the mesoscopic scale. Such a volume may contain a large number of grains of austenite (A), martensite $(M)$, or of both austenite and martensite $(A+M)$. A representative situation of this schematic view is suggested by SEM observations of a NiTi sample, see Figure 3. At the local scale, blue boundaries highlight austenite grains (A), red boundaries martensite grains $(\mathrm{M})$, and red-blue boundaries mixed austenitemartensite grains $(\mathrm{A}+\mathrm{M})$.

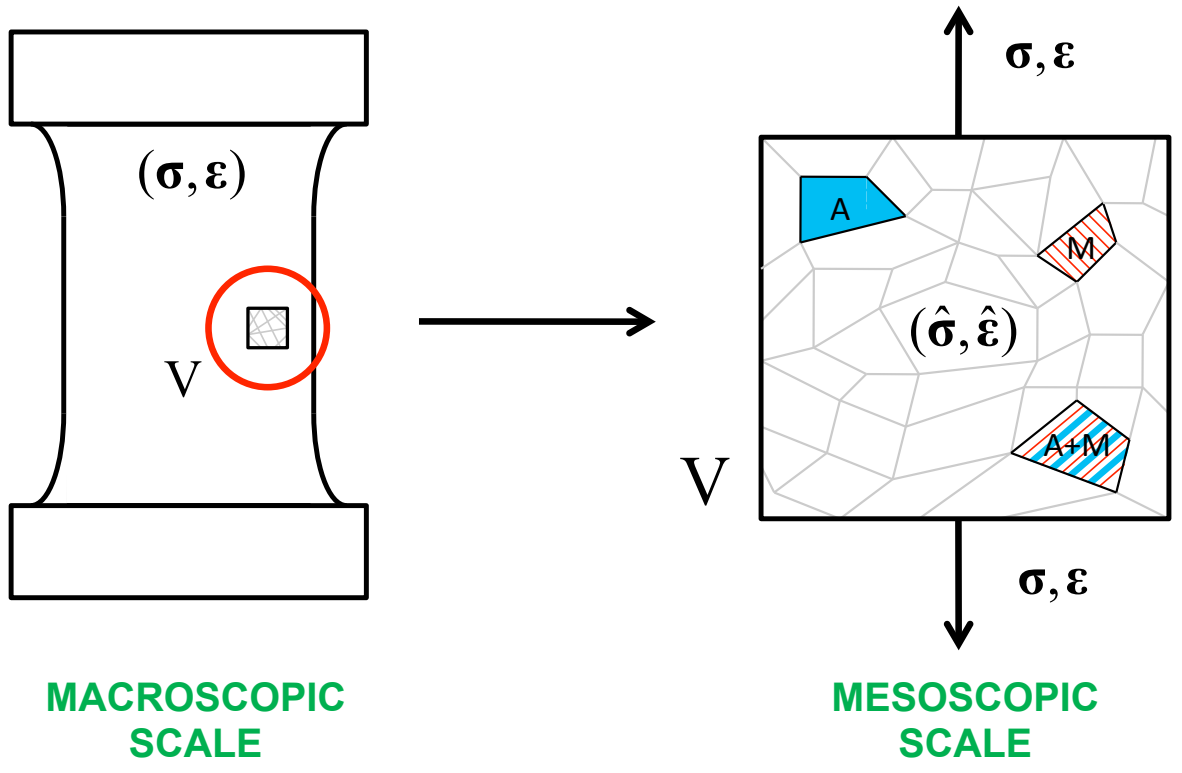

Figure 2: Schematic representation of the macroscopic scale of the SMA specimen and the mescopic scale of the RVE. The RVE consists of a set of austenite (A), martensite (M) or mixed grains containing martensite and austenite $(\mathrm{A}+\mathrm{M})$ in the form of bands.

The loading of the REV by macroscopic stress $\boldsymbol{\sigma}$, strain $\boldsymbol{\varepsilon}$, and inelastic strain $\boldsymbol{\alpha}$ is computed through standard continuum theory (macroscale). To evaluate the mesoscopic state, i.e. mesoscopic stress $\hat{\boldsymbol{\sigma}}$, strain $\hat{\boldsymbol{\varepsilon}}$, and inelastic strain $\hat{\boldsymbol{\alpha}}$, several homog- 


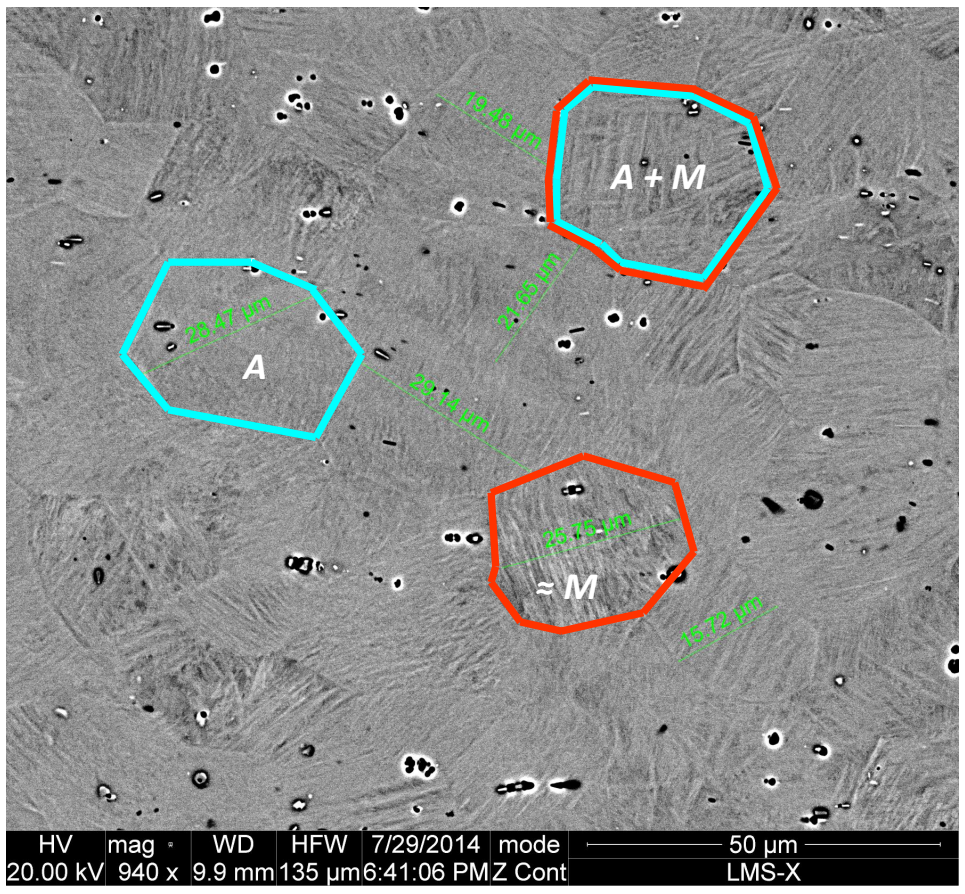

Figure 3: SEM image of a NiTi sample: local material scale. Blue boundaries highlight austenite grains (A), red boundaries martensite grains $(M)$, and red-blue boundaries mixed austenite-martensite grains $(A+M)$.

enization techniques have been considered in the literature for metallic structures (Bui et al., 1981; Cano et al., 2004; Dang Van et al., 1989). In order to obtain a simple closed formula for the fatigue criterion, we adopt a Lin-Taylor's homogenization scheme (Lin, 1957; Taylor, 1938), based on the equality of macroscopic and mesoscopic strains:

$$
\boldsymbol{\varepsilon}=\hat{\boldsymbol{\varepsilon}}
$$

From the expressions of the elastic Hooke's law at the macroscopic and mesoscopic scale, we deduce (Cano et al., 2004; Dang Van, 1999):

$$
\hat{\boldsymbol{\sigma}}=\mathbb{A}: \boldsymbol{\sigma}-\mathbb{A}: \mathbb{C}:(\hat{\boldsymbol{\alpha}}-\boldsymbol{\alpha})
$$

where the fourth-order tensor $\mathbb{A}$ is the localization tensor. As commonly accepted in fatigue problems (Dang Van, 1973, 1999; Dang Van et al., 1989; Maitournam et al., 2011; Morel, 2000b; Papadopoulos, 2001), it is assumed $\mathbb{A}=\mathbb{I}, \mathbb{I}$ being the fourth-order identity tensor. As stated previously, the macroscopic stiffness tensor $\mathbb{C}$ and consequently 
the mesoscopic stiffness tensor $\widehat{\mathbb{C}}$ depend on the components of the internal variables $\boldsymbol{\alpha}$ and $\hat{\boldsymbol{\alpha}}$ describing phase transformation of SMA. A similar dependence is also assumed, respectively, for the macroscopic $\mathbb{L}$ and mesoscopic $\hat{\mathbb{L}}$ compliance tensors.

The Lin-Taylor scheme is known to provide a stiff response in the homogenization theory (Zaoui, 1987). However, since the results are here used to justify measures of the stress path and not intrinsic values, it will not affect the obtained fatigue predictions, as shown in the examples discussed in the following. Such a choice has already been tested in case of polycrystalline metals (Hofmann et al., 2009).

\subsection{Fatigue criterion}

In high cycle fatigue, when the loading is close to infinite lifetime, a commonly accepted assumption is that each point material is in an elastic shakedown state. Therefore, $\boldsymbol{\alpha}$ and $\hat{\boldsymbol{\alpha}}$ are constant during the cyclic loading (see Section 2.2). Then, according to the shakedown theorem (see Eq. (8)), a time-independent field $\mathbf{A}_{*}^{r}$ can be defined such that:

$$
\hat{\boldsymbol{\sigma}}(t)=\boldsymbol{\sigma}(t)-\mathbf{A}_{*}^{r} \quad \text { with } \quad \mathbf{A}_{*}^{r}=\mathbb{C}:(\hat{\boldsymbol{\alpha}}-\boldsymbol{\alpha})
$$

As it can be observed, given the computed $\boldsymbol{\sigma}(t)$, the mesoscopic stress tensor $\hat{\boldsymbol{\sigma}}$ is known at each time if the residual stress $\mathbf{A}_{*}^{r}$ is known. The residual stress $\mathbf{A}_{*}^{r}$ can not be directly computed without the exact knowledge of the microstructure and its evolution up to the shakedown state. As in the formulation of the Dang Van criterion by Papadopoulos (1987), we shall compute the smallest hypersphere encompassing the path of the deviatoric stress $\mathbf{s}$. Then, $\mathbf{A}_{*}^{r}$ is the center of such hypersphere, that is the solution of the following min-max problem:

$$
\mathbf{A}_{*}^{r}=\min _{\mathbf{A}_{1}^{r}} \max _{t}\left\|\mathbf{s}(t)-\mathbf{A}_{1}^{r}\right\|
$$

The mesoscopic shear stress $\hat{\tau}(t)$ can be calculated once computed $\hat{\boldsymbol{\sigma}}$ from Eq. (14):

$$
\hat{\tau}(t)=\frac{\hat{\sigma}_{I}(t)-\hat{\sigma}_{I I I}(t)}{2}
$$


where $\hat{\sigma}_{I}, \hat{\sigma}_{I I}, \hat{\sigma}_{I I I}$ are the principal stresses, with $\hat{\sigma}_{I} \geq \hat{\sigma}_{I I} \geq \hat{\sigma}_{I I I}$. Similarly, the mesoscopic hydrostatic stress can be computed as follows:

$$
\hat{\sigma}_{h}(t)=\frac{1}{3} \operatorname{tr}(\hat{\boldsymbol{\sigma}}(t))
$$

In the case of $\boldsymbol{\alpha}$ deviatoric (as in the case of the Souza-Auricchio model), it yields $\sigma_{h}=\hat{\sigma}_{h}$ (Dang Van et al., 1989).

Since it is well known that the hydrostatic part of the stress plays an important role in crack opening, evolution of damage, and implicitly in fatigue lifetime (Schijve, 2009), we propose to consider a fatigue criterion, defined by:

Dang Van (DV) fatigue criterion for SMAs. Let us consider a structure subjected to cyclic loading and resulting in an elastic shakedown state at both macroscopic and mesoscopic scale. If

$$
\max _{t}\left\{\hat{\tau}(t)+a(\boldsymbol{\alpha}) \hat{\sigma}_{h}\right\} \leq b(\boldsymbol{\alpha})
$$

for all points of the structure, then fatigue crack initiation will not occur.

The safety domain in the stress space $\left(\sigma_{h}, \hat{\boldsymbol{\tau}}\right)$ is delimited by a straight line, denoted next as $D V$ line. Figure 4 shows the splitting of the stress space in the infinite and finite lifetime by the DV line (red). The lifetime of a component will be infinite if the stress path lies below the DV line or will be finite if at least one of the points lies above the same line (see the grey dotted curve of Figure 4); if any point of the loading path is located above the DV line, life will be finite and fatigue crack initiation will occur (see the black curve of Figure 4).

Parameters $a$ and $b$, introduced in Eq. 18 and defining the DV line, are material constants usually identified on classical uniaxial fatigue experiments in tension and/or torsion (Dang Van, 1999). As $a$ and $b$ are computed from experiments at $N$ cycles, we shall use the notation $a_{N}$ and $b_{N}$, where subscript $N$ stands for the number of run-out cycles of the experiments used to calibrate the model (Ferjani et al., 2011a,b; Wackers et al., 2010a). Moreover, such parameters are assumed to depend on the internal variable $\boldsymbol{\alpha}$, as verified by the numerical simulations presented in Section 4 . This allows to obtain a set of DV lines in the stress space $\left(\sigma_{h}, \hat{\boldsymbol{\tau}}\right)$ for fixed number of cycles $N$. Each 


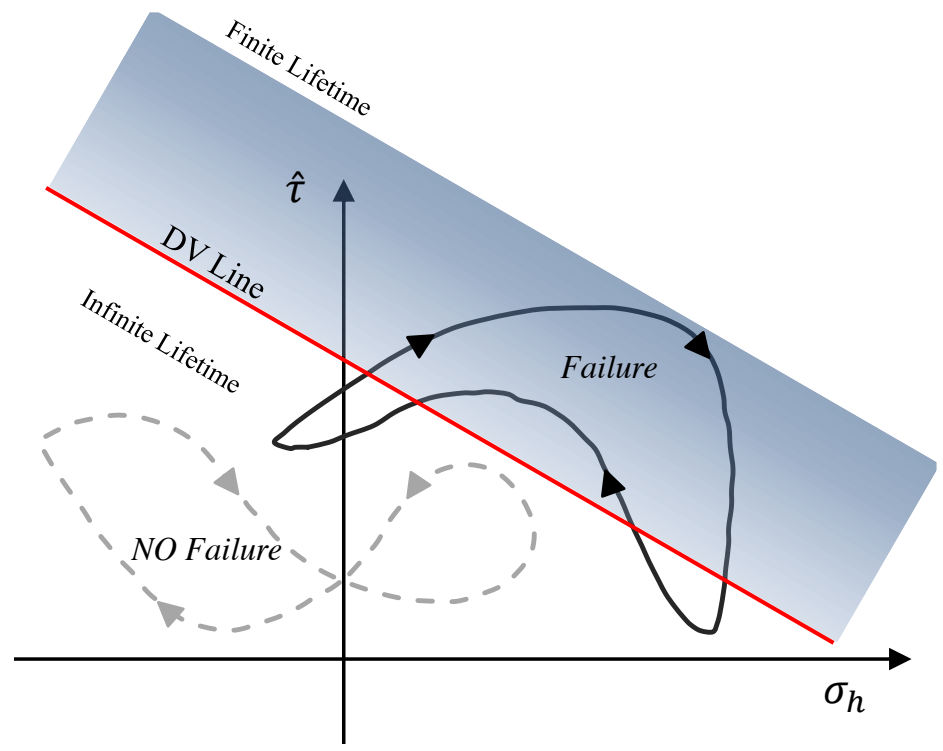

Figure 4: Illustration of the Dang Van (DV) criterion in the $\left(\sigma_{h}, \hat{\boldsymbol{\tau}}\right)$ plane. The stress space is split in the infinite and finite lifetime by the DV line (red).

line is defined by an internal variable $\boldsymbol{\alpha}$. As an illustrative example, a set of DV lines, each defined for a fixed value of the martensite volume fraction $0<z<1$ and number of cycles $N$, is represented in Figure 5.

To evaluate the mesoscopic stress path $\left(\sigma_{h}, \hat{\boldsymbol{\tau}}\right)$ we employ an algorithm similar to that employed for the classical DV criterion (Bernasconi, 2002). In particular, the criterion is computed as post-processing of the mechanical fields obtained by the simulation described in Section 4 and the post-process is performed with the Matlab implementation of the optimization code SDPT3 (Tütüncü et al., 2003). Details about the algorithm are given in Appendix A.

\section{EXAMPLE OF SMA APPLICATIONS}

\subsection{Experimental data and model calibration}

The papers by Pelton and coworkers (Pelton, 2011; Pelton et al., 2003, 2008) report detailed experimental results from fatigue data collected on NiTi microdogboneand diamond-shaped specimens, as well as on stents. For the sake of completeness of 


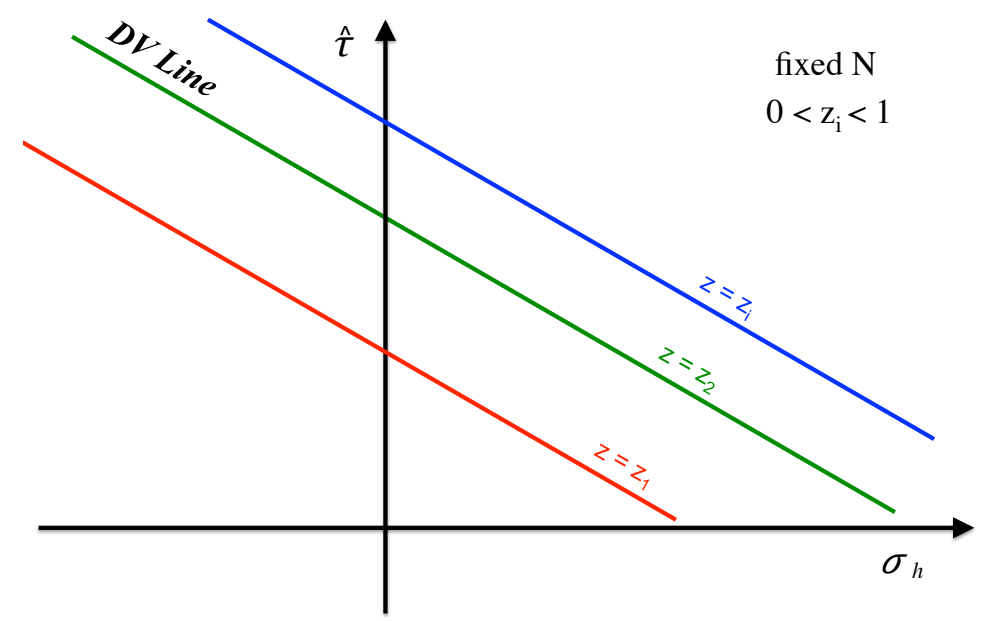

Figure 5: Set of Dang Van (DV) lines in the stress space $\left(\sigma_{h}, \hat{\tau}\right)$ for $N$ fixed. Each line is defined by a fixed value of the martensite volume fraction $0<z<1$.

available data, in the present work we refer to the set of uniaxial experimental results by Pelton (2011), related to microdogbone specimens with $6 \mathrm{~mm}$ gauge length, $0.3 \mathrm{~mm}$ gauge width, and $0.15 \mathrm{~mm}$ gauge thickness. The specimens were extracted from stentlike devices that were laser machined from thermomechanically processed $\mathrm{Ni}_{50.8} \mathrm{Ti}_{49.2}$ tubing, subsequently expanded and thermally shape-set into their final dimensions. The design and manufacturing conditions led to an austenite finish $\left(A_{f}\right)$ temperature of $20^{\circ} \mathrm{C}$, i.e. comparable to the $A_{f}$ temperature of other NiTi self-expanding peripheral stents (Pelton, 2011). Such uniaxial fatigue experiments in tension will allow to calibrate the DV parameters $a$ and $b$.

The Souza-Auricchio model is herein adopted to simulate the experimental tests and Table 1 reports the model parameters, identified according to the procedure reported in (Auricchio et al., 2009a). The experimental monotonic pseudoelastic stressstrain curve at $37^{\circ} \mathrm{C}$ (i.e. at the temperature of the considered fatigue tests) is reported in Figure 6 (red dotted line), superimposed on the predicted one (blue line).

With regard to fatigue test conditions, the microdogbone specimens were prestrained at $37^{\circ} \mathrm{C}$ to $9 \%$ (beyond the stress plateau) and then fatigued from the unloading plateau. Particularly, the specimens were cycled, either up to fracture or up to $10^{7}$ cycles (run-out), with various combinations of mean strain and strain amplitude. 
Table 1: Calibrated parameters of the Souza-Auricchio model in a one-dimensional setting; see Auricchio et al. (2009a,b).

\begin{tabular}{lccc}
\hline Parameter description & Symbol & Value & Units \\
\hline Initial elastic modulus & $E_{i}$ & 38000 & $\mathrm{MPa}$ \\
Final elastic modulus & $E_{f}$ & 11000 & $\mathrm{MPa}$ \\
Maximum transformation strain & $\varepsilon_{L}$ & 4.49 & $\%$ \\
Stress-strain slope measure during transformation & $h$ & 290 & $\mathrm{MPa}$ \\
Elastic domain radius & $R$ & 148 & $\mathrm{MPa}$ \\
Slope of $\theta^{*}$ with respect to temperature & $\beta$ & 9.50 & $\mathrm{MPa} /{ }^{\circ} \mathrm{C}$ \\
Reference temperature & $\theta^{*}$ & 278.55 & ${ }^{\circ} \mathrm{C}$ \\
Regularization parameter & $\delta$ & $10^{-12}$ & - \\
\hline
\end{tabular}

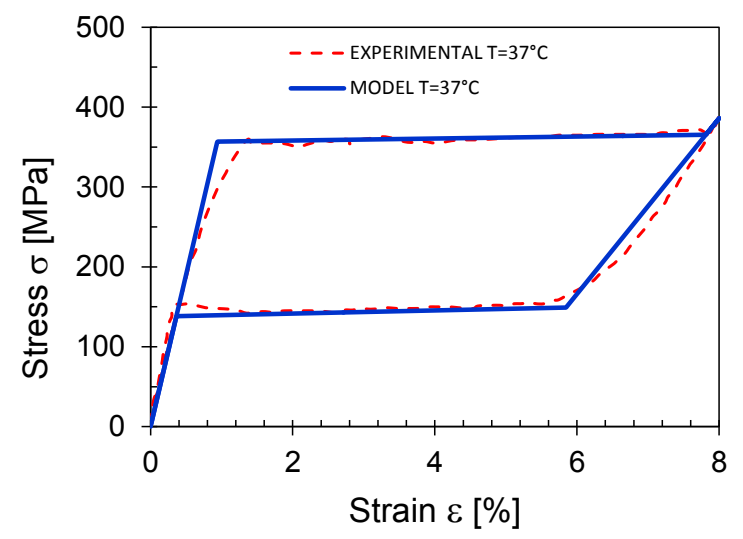

Figure 6: Experimental (red dotted line) (Pelton, 2011) and numerical (blue line) monotonic stress-strain curves related to a NiTi microdogbone specimen tested at a constant temperature of $37^{\circ} \mathrm{C}$.

Figure 7(a) reports the experimental results obtained by Pelton (2011) as constant-life diagram, where the different conditions of mean strain and strain amplitude are displayed. The specimens that survived $10^{7}$ cycles are shown as blue triangles, whereas specimens that fractured are shown as red circles.

For all the mean strain-strain amplitude cases reported in Figure 7(a), we first try to establish which data are possibly related to the elastic shakedown condition, i.e. the 


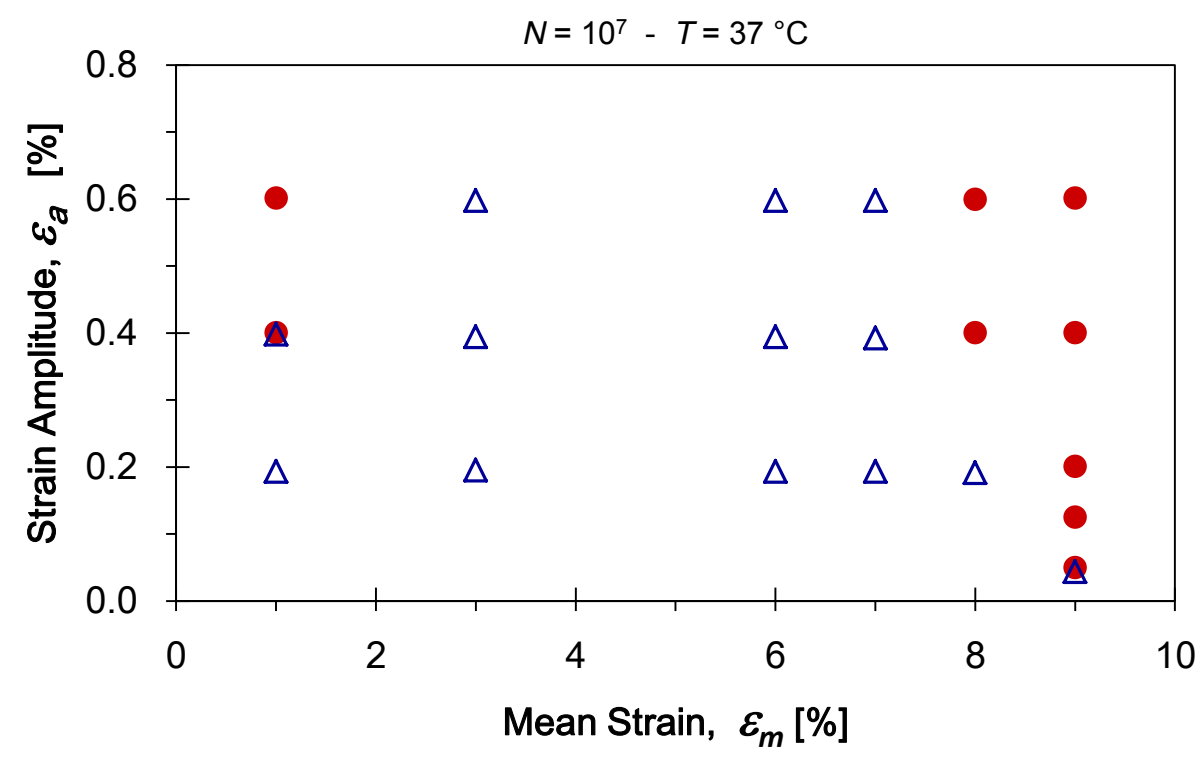

(a)

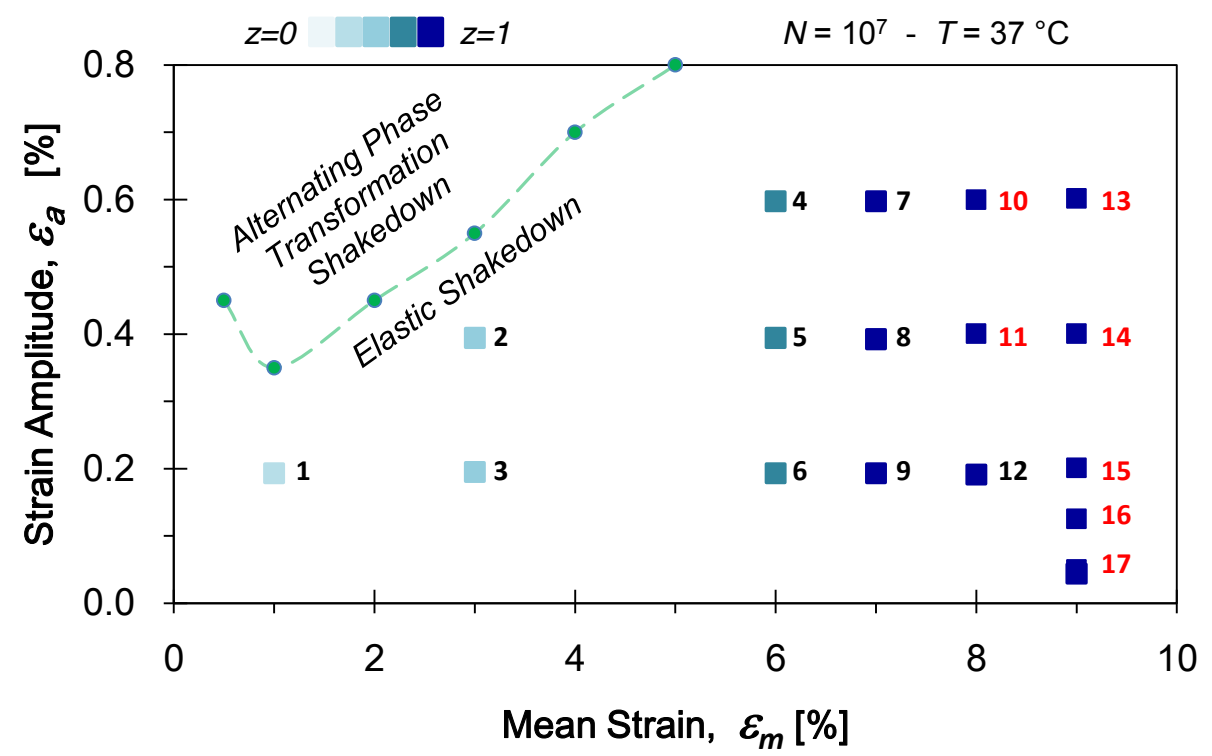

(b)

Figure 7: Constant-life diagram. (a) Experimental data by Pelton (2011). Conditions that survived the $10^{7}$ cycles testing are shown as blue triangles, whereas cyclic conditions that fractured as red circles. (b) The green curve distinguishes between the elastic and phase transformation shakedown subspaces. The experimental data considered in the present work are numbered (red numbers refer to specimens that fractured). The color map indicates martensite formation. 
case of interest for the present study. Numerical simulations of all the cases permit to split the constant-life diagram shown in Figure 7(b) into two subspaces, referring to elastic and alternating phase transformation shakedown, respectively. The experimental data by Pelton (2011), resulting in elastic shakedown, are numbered in Figure 7(b), while those resulting in phase transformation shakedown are not considered in the present work.

From the numerical simulations we also obtain that the several combinations of mean strain and strain amplitude give rise to different values of the martensite volume fraction $z$. As it can be observed from Figure 7(b), the formation of martensite is responsible for an increasing of the elastic shakedown domain between 1 and $6 \%$ mean strain. Table 2 reports the computed values of $z$ and along with the Young's modulus $E=E(z)$ for the fatigue cases numbered in Figure 7(b).

\subsection{Fatigue analysis}

We start by considering the cases of Table 2 showing a fully martensitic transformation $(z=1)$, i.e. fatigue loading is applied on a fully transformed material. In particular, we consider the experimental points numbered from 7 to 17 in Figure 7(b). As an example, Figures 8 and 9 report some representative loading curves in terms of macroscopic stress and strain.

The DV criterion is then implemented to predict failure for the considered cases. Figure 10 represents the DV diagram in terms of mesoscopic shear stress, $\hat{\tau}$, and hydrostatic stress, $\sigma_{h}$, where the loading paths generated by the simulations of the experimental specimens are represented. The obtained V-shape is a consequence of the simulation of the considered uniaxial tests. As it can be observed in Figure 10, material behavior in the DV diagram is similar to that classically observed for metals. In particular, by increasing the strain amplitude at constant mean strain, an increase of the only mesoscopic shear stress is determined; see, e.g., cases 7, 8, and 9 in Figure 10. Similarly, by increasing the mean strain at constant strain amplitude determines the increase of the only hydrostatic stress; see, e.g., cases 7, 10, and 13 in Figure 10.

The calibrated DV line (green line) is also represented in Figure 10. The DV parameters, $a_{10^{7}}$ and $b_{10^{7}}$, are calibrated by using the loading paths related to cases 11 
Table 2: Summary of the experimental cases by Pelton (2011), considered in the present work and numbered in Figure 7(b). Computed values of the martensite volume fraction $z$ and Young's modulus $E=E(z)$.

\begin{tabular}{c|ccc|cc}
\hline Case & \multicolumn{2}{|c|}{ Experiments from Pelton (2011) } & \multicolumn{2}{c}{ Numerical simulations } \\
& $\epsilon_{a}[\%]$ & $\epsilon_{m}[\%]$ & Fatigue life & $z$ & $E(z)[\mathrm{MPa}]$ \\
\hline 1 & 0.2 & 1 & Run-out & 0.08 & 31730 \\
2 & 0.4 & 3 & Run-out & 0.41 & 18917 \\
3 & 0.2 & 3 & Run-out & 0.45 & 18109 \\
4 & 0.6 & 6 & Run-out & 0.92 & 11666 \\
5 & 0.4 & 6 & Run-out & 0.96 & 11357 \\
6 & 0.2 & 6 & Run-out & 0.99 & 11064 \\
7 & 0.6 & 7 & Run-out & 1 & 11000 \\
8 & 0.4 & 7 & Run-out & 1 & 11000 \\
9 & 0.2 & 7 & Run-out & 1 & 11000 \\
10 & 0.6 & 8 & Failure & 1 & 11000 \\
11 & 0.4 & 8 & Failure & 1 & 11000 \\
12 & 0.2 & 8 & Run-out & 1 & 11000 \\
13 & 0.6 & 9 & Failure & 1 & 11000 \\
14 & 0.4 & 9 & Failure & 1 & 11000 \\
15 & 0.2 & 9 & Failure & 1 & 11000 \\
16 & 0.1 & 9 & Failure & 1 & 11000 \\
17 & 0.05 & 9 & Run-out/Failure & 1 & 11000 \\
\hline & & & &
\end{tabular}

and 17 , that fractured, and result:

$$
\left\{\begin{array}{l}
a_{10^{7}}=0.808 \\
b_{10^{7}}=137.770 \mathrm{MPa}
\end{array}\right.
$$

It should be remarked that the calibrated DV parameters refer to $10^{7}$ cycles (i.e. $N=$ $\left.10^{7}\right)$.

Once determined the DV line, we can verify the other fatigue experimental results by Pelton (2011). As it can be observed in Figure 10, cases 7, 8, 9, 12, and 17 do not 


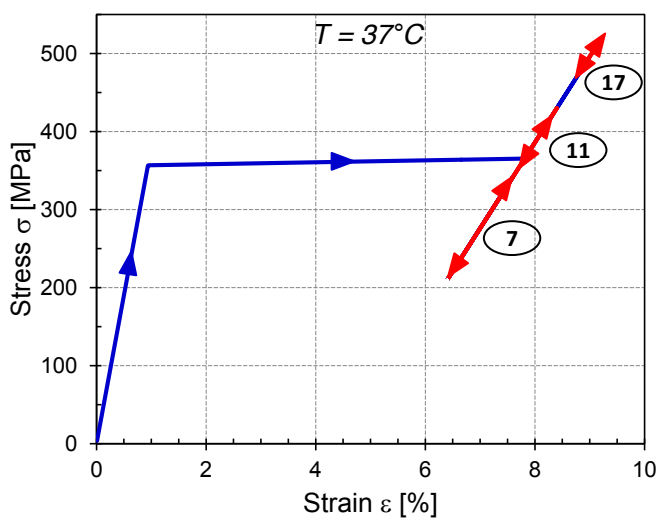

Figure 8: Representative loading cases of Table 2, showing a fully martensitic transformation $(z=1)$. Macroscopic stress-strain curve for $7 \%$ mean strain and $0.6 \%$ strain amplitude (case 7 ); $8 \%$ mean strain and $0.4 \%$ strain amplitude (case 11 ); $9 \%$ mean strain and $0.05 \%$ strain amplitude (case 17 ).

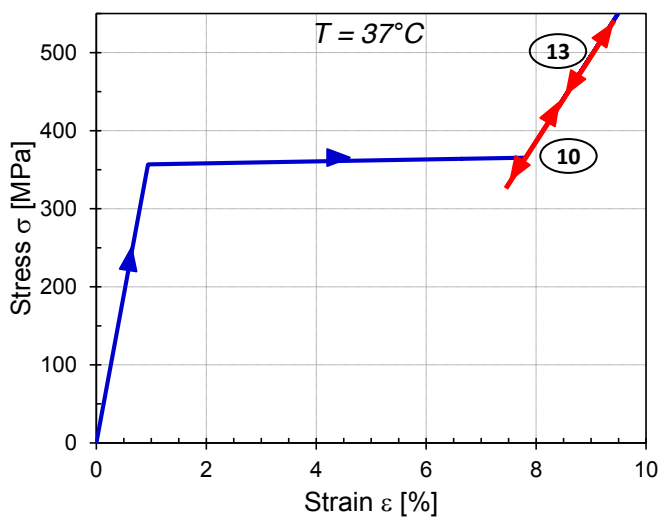

Figure 9: Representative loading cases of Table 2, showing a fully martensitic transformation $(z=1)$. Macroscopic stress-strain curve for $0.6 \%$ strain amplitude and different mean strains: $8 \%$ for case 10 and $9 \%$ for case 13 .

result in failure, while cases $10,11,13,14,15$, and 16 fail. The predicted results are in agreement with experiments of Figure 7(a).

Now, we consider the cases reported by Pelton (2011) which show the coexistence of austenitic and martensitic phases $(0<z<1)$, as reported in Table 2, i.e. referring to fatigue loading acting on the unloading plateau. In particular, we consider the experimental points numbered from 1 to 6 in Figure 7(b). As an example, Figure 11 reports 


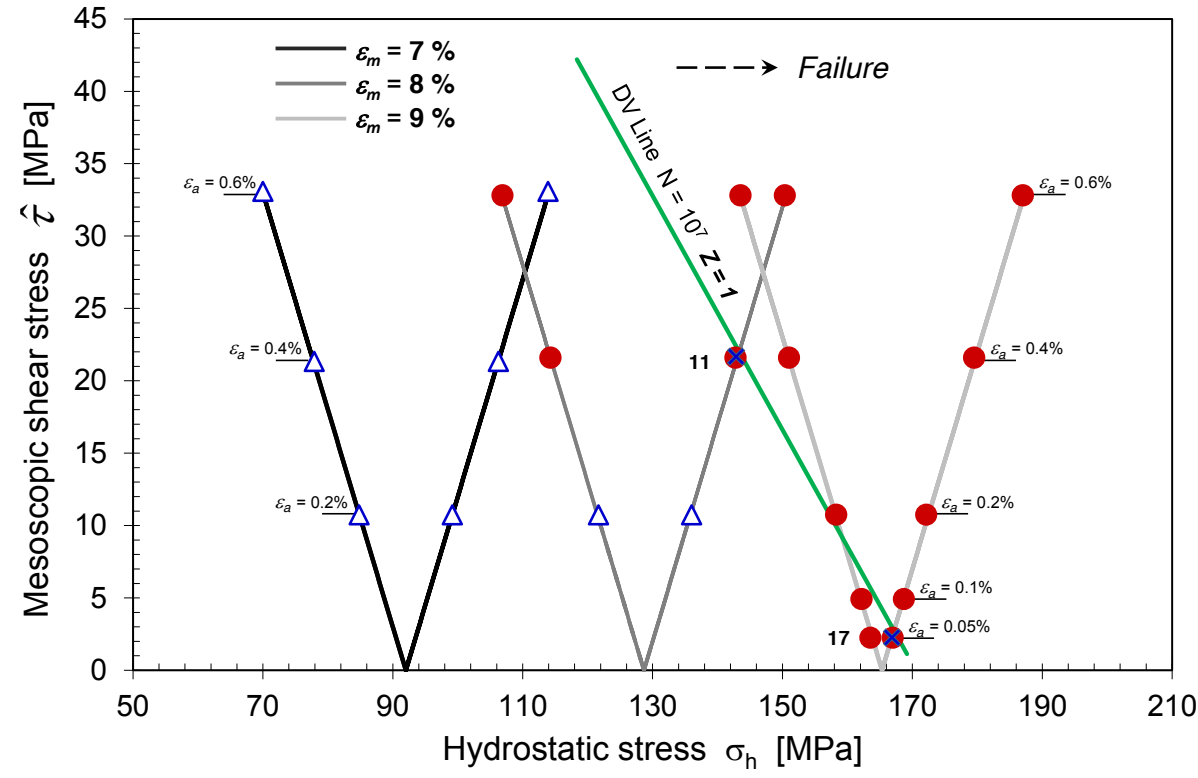

Figure 10: Calibrated DV line (green) in the hydrostatic-mesoscopic stress plane and loading paths of cases 7-17 of Table 2 showing a fully martensitic transformation $(z=1)$.

two representative loading curves in terms of macroscopic stress and strain.

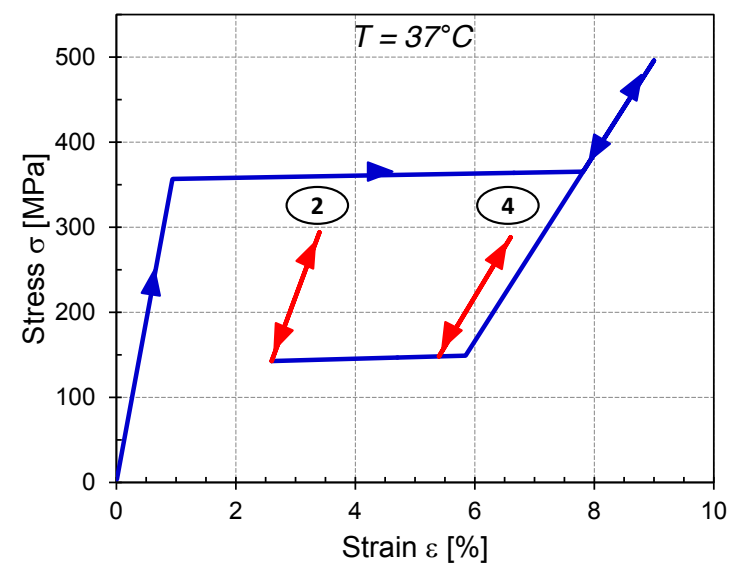

Figure 11: Representative loading cases of Table 2 showing the coexistence of austenitic and martensitic phases $(0<z<1)$. Macroscopic stress-strain curve for $3 \%$ mean strain and $0.4 \%$ strain amplitude (case 2); $6 \%$ mean strain and $0.6 \%$ strain amplitude (case 4 ).

Figure 12 represents the DV diagram in terms of mesoscopic shear stress, $\hat{\tau}$, and 
hydrostatic stress, $\sigma_{h}$, where the loading paths generated by the simulations of the experimental cases are represented. As it can be observed, in such a mixed domain, material behavior in the DV diagram presents significant differences compared to that classically observed for metals. In particular, by increasing the strain amplitude at constant mean strain, it triggers the increase of both mesoscopic shear and hydrostatic stresses and the decrease of martensite fraction (see Table 2); see, e.g., cases 2 and 3 in Figure 12. Increasing the mean strain at constant strain amplitude determines the decrease of both mesoscopic shear and hydrostatic stresses and the increase of martensite fraction (see Table 2); see, e.g., cases 1, 3, and 6 or 2, 5 in Figure 12.

The DV line (green line) is also represented in Figure 12. The line is assumed to have the same slope of that obtained for the range $7-9 \%$ mean strain, i.e. $a_{10^{7}}$ does not depend on $z$. On the contrary, $b_{10^{7}}$ parameter depends on $z$, which ranges between 0 and 1 . This means that fatigue limit varies with $z$, but not with triaxiality. Such an assumption (standard for metallic alloys (Fares et al., 2006; Ferjani et al., 2011a)) is arbitrary due to the absence of more experimental data (failed specimens) and will need to be investigated in future works. In fact, experimental data reveal that no fracture is attained for mean strains between 1 and $6 \%$ and strain amplitudes between 0.2 and $0.6 \%$, thus indicating that there are insufficient data for a complete analysis within this range to provide the $b_{10^{7}}$ value.

Figures 13(a) and (b) show the dependency of the mesoscopic shear stress $\hat{\tau}$ and hydrostatic stress $\sigma_{h}$ on the martensite fraction $z$, respectively, for the cases 1-6. Note that $\hat{\tau}$ and $\sigma_{h}$ show the same dependence on $z$ : cases with equal strain amplitude (1, 3 , and 6 or 2 and 5) show a decrease of $\hat{\tau}$ and $\sigma_{h}$ with increasing mean strain and $z$; cases with equal mean strain ( 2 and 3 , or 4,5 , and 6 ) show a decrease of $\hat{\tau}$ and $\sigma_{h}$ with decreasing strain amplitude and increasing $z$.

The obtained results are in accordance with experimental observations by Pelton (2011), demonstrating that, between 1 and 7\% mean strain, NiTi-based SMAs can accommodate larger strain amplitude, for a given fatigue life. Therefore, above a mean strain of $1 \%$ and within elastic shakedown, the fatigue life appears to increase with increasing mean strain, thus indicating that the formation of stress-induced martensite may be responsible for such a behavior (Pelton, 2011). This implies that microstruc- 


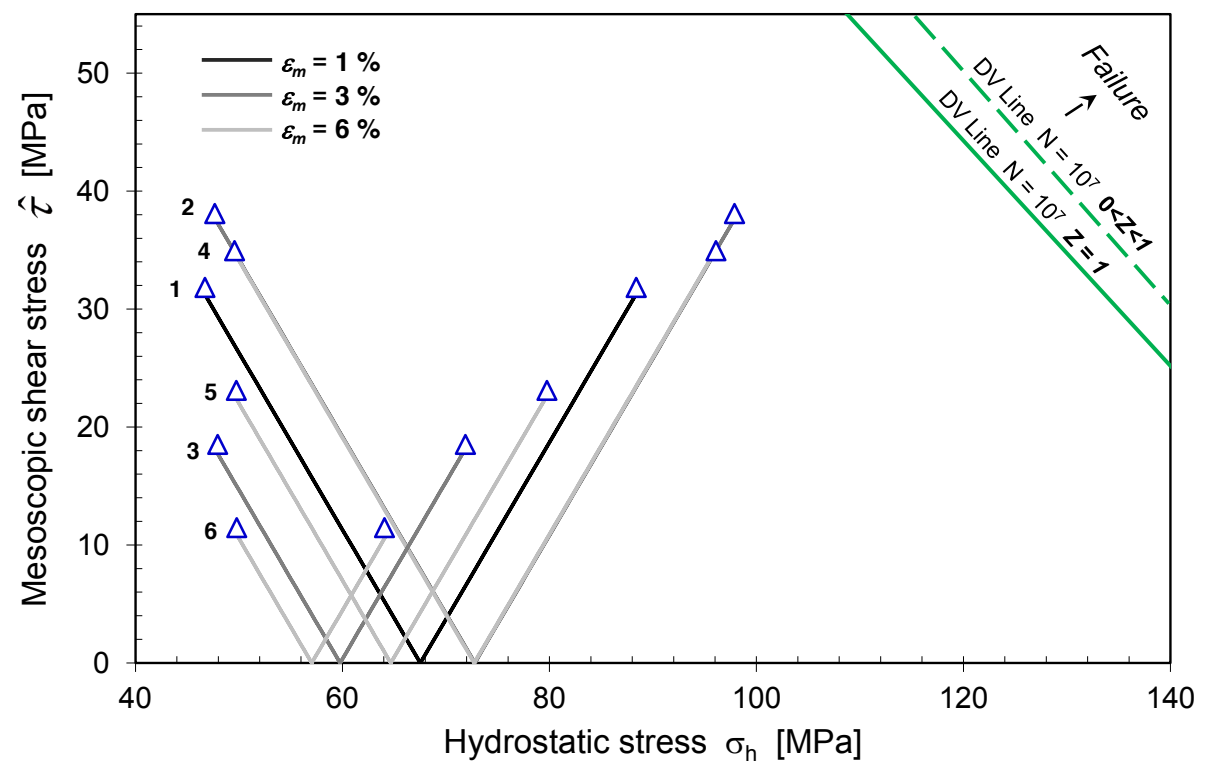

Figure 12: Calibrated DV line (green) in the hydrostatic-mesoscopic stress plane and loading paths of cases 1-6 of Table 2 showing the coexistence of austenitic and martensitic phases $(0<z<1)$.

tural effects due to formation of stress-induced martensite (whose volume fraction increases as mean strain increases) or the effects due to the lower moduli in the stressinduced transformation regime (i.e. decreased hysteresis energy) can lead to longer fatigue lives, than the presence of fully austenite or martensite. The work by Ono and Sato (1988) shows in fact that few selected variants of stress-induced martensite reduce the internal strains due to the transformation. On the contrary, above $7 \%$ mean strain (approximately fully martensitic phase at $37^{\circ} \mathrm{C}$ ), the constant life data exhibit a negative slope. No experimental data are available for the case of fully austenitic transformation $(z=0)$ for the considered SMA material.

\section{CONCLUSIONS AND PERSPECTIVES}

This paper has investigated the elastic shakedown behaviour of SMA materials and has presented the extension of the DV high cycle fatigue criterion to SMAs. The proposed formulation is general and suitable to several SMA constitutive laws, combining both plastic and transformation strains as well as thermal and mechanical cycling. The 


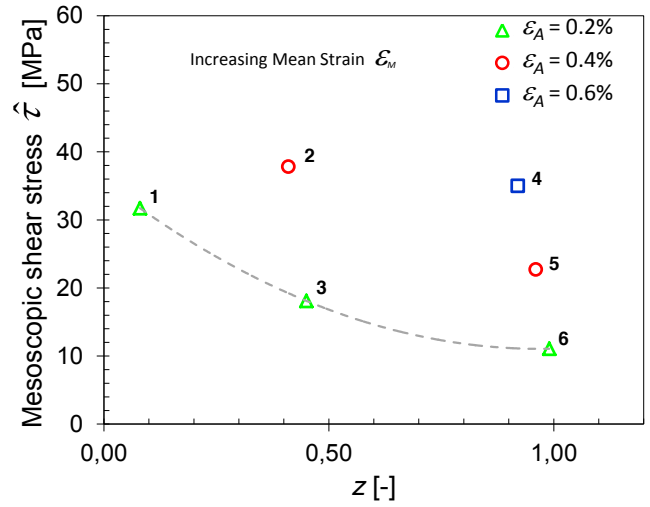

(a)

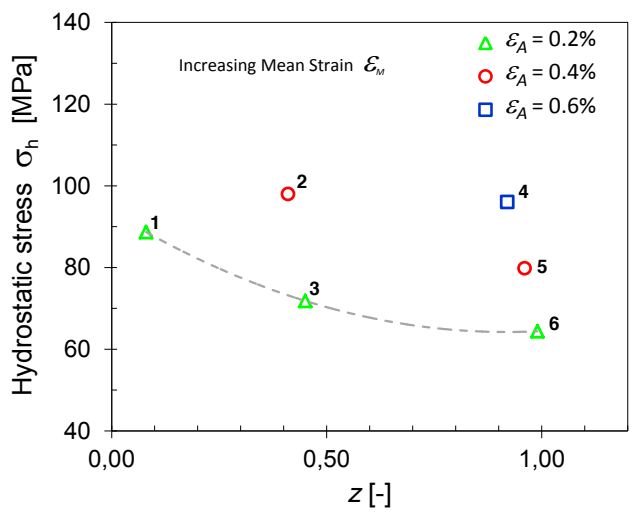

(b)

Figure 13: Dependency (a) of the mesoscopic shear stress $\hat{\tau}$ and (b) of the hydrostatic stress $\sigma_{h}$ on martensite fraction $z$.

theoretical extension has been applied to uniaxial experimental data taken from the literature. The obtained results demonstrate the possibility to define a DV-type two-scale criterion to predict fatigue crack initiation in SMA materials, suitable also for multiaxial loadings. However, some important issues are still unresolved and demand further investigation. First, the criterion needs to be applied to different experimental loading cases for its complete validation to the multiaxial case. This will allow to deeply investigate the dependence of the DV parameters on martensite volume fraction. Second, 
as the proposed approach is clearly phenomenological, further investigation involving observations of the evolution of SMA microstructure during such a type of cyclic loading and its relation to fatigue are also needed. This will provide additional insight into microscopic deformation mechanisms and into factors influencing both crack initiation and growth. Finally, methods for the fast identification of fatigue limits, like the infrared thermography measurements (generally applied to steels), should be employed also for SMAs.

\section{Acknowledgement}

This work is partially funded by Ministero dell'Istruzione, dell'Università e della Ricerca through the Project no. 2010BFXRHS and by the Italian-French University (UIF-UIF) through the 'Bando Galileo 2013-2014' Grant no. 148-30174T J. C. Menna acknowledges Programma Star of University of Naples, Federico II - Sostegno Territoriale alle Attività di Ricerca, Linea d'Intervento 2 - Mobilità Giovani Ricercatori.

\section{Appendix A. Algorithmic scheme for the computation of the DV fatigue criterion}

The general algorithmic scheme employed for the computation of the DV fatigue criterion is composed of the following steps (Bernasconi, 2002; Dang Van et al., 1989):

1. calculate the stabilized macroscopic stress $\boldsymbol{\sigma}(t)$ in each point of the structure;

2. split the macroscopic stress $\boldsymbol{\sigma}(t)$ in its hydrostatic and deviatoric part, defined respectively as:

$$
\left\{\begin{array}{l}
\sigma_{h}(t)=\frac{1}{3} \operatorname{tr}(\boldsymbol{\sigma}(t)) \\
\mathbf{s}(t)=\boldsymbol{\sigma}(t)-\sigma_{h}(t) \mathbf{I}
\end{array}\right.
$$

3. calculate the center $\mathbf{A}_{r}^{*}$ of the smallest hypersphere circumscribing the stress path through the following min-max problem:

$$
\mathbf{A}_{*}^{r}=\min _{\mathbf{A}_{1}^{r}} \max _{t}\left\|\boldsymbol{\sigma}(t)-\mathbf{A}_{1}^{r}\right\|
$$


4. calculate the mesoscopic stress $\hat{\boldsymbol{\sigma}}(t)$ :

$$
\hat{\boldsymbol{\sigma}}(t)=\boldsymbol{\sigma}(t)-\mathbf{A}_{*}^{r}
$$

5. calculate the mesoscopic shear stress $\hat{\tau}(t)$ :

$$
\hat{\tau}(t)=\frac{\hat{\sigma}_{I}(t)-\hat{\sigma}_{I I I}(t)}{2}
$$

where $\hat{\sigma}_{I}, \hat{\sigma}_{I I}, \hat{\sigma}_{I I I}$ are the principal stresses, with $\hat{\sigma}_{I} \geq \hat{\sigma}_{I I} \geq \hat{\sigma}_{I I I}$.

6. calculate the fatigue indicator:

$$
\max _{t}\left\{\hat{\tau}(t)+a(\boldsymbol{\alpha}) \hat{\sigma}_{h}\right\}-b(\boldsymbol{\alpha})
$$

where $\hat{\sigma}_{h}=\sigma_{h}$.

\section{References}

Asgarian, B., Moradi, S., 2011. Seismic response of steel braced frames with shape memory alloy braces. Journal of Constructional Steel Research 67 (1), 65-74.

Auricchio, F., Coda, A., Reali, A., Urbano, M., 2009a. SMA numerical modeling versus experimental results: parameter identification and model prediction capabilities. J. Mater. Eng. Perform. 18, 649-654.

Auricchio, F., Petrini, L., 2004. A three-dimensional model describing stresstemperature induced solid phase transformations: solution algorithm and boundary value problems. Int. J. Numer. Methods Eng. 6, 807-836.

Auricchio, F., Reali, A., Stefanelli, U., 2009b. A macroscopic 1D model for shape memory alloys including asymmetric behaviors and transformation-dependent elastic properties. Comput. Methods in Appl. Mech. Eng. 198, 1631-1637.

Azaouzi, M., Lebaal, N., Makradi, A., Belouettar, S., 2013. Optimization based simulation of self-expanding Nitinol stent. Mater. Design 50, 917-928.

Barney, M., Xu, D., Robertson, S., Schroeder, V., Ritchie, R.O. andPelton, A., Meht, A., 2011. Impact of thermomechanical texture on the superelastic response of nitinol implants. Journal of the Mechanical Behavior of Biomedical Materials 4, 14311439. 
Bernasconi, A., 2002. Efficient algorithms for calculation of shear stress amplitude and amplitude of the second invariant of the stress deviator in fatigue criteria applications. International Journal of Fatigue 24 (6), 649-657.

Bertolino, G., Constantinescu, A., Ferjani, M., Treiber, P., 2007. A multiscale approach of fatigue and shakedown for notched structures. Theoretical and Applied Fracture Mechanics 48 (2), 140-151.

Bosia, S., Constantinescu, A., 2012. Fast time-scale average for a mesoscopic high cycle fatigue criterion. International Journal of Fatigue 45, 39-47.

Brinson, L., Schmidt, I., Lammering, R., 2004. Stress-induced transformation behavior of a polycrystalline niti shape memory alloy: micro and macromechanical investigations via in situ optical microscopy. Journal of the Mechanics and Physics of Solids $52(7), 1549-1571$.

Bui, H., Dang Van, K., Stolz, C., 1981. Relations entre grandeurs microscopiques et macroscopiques. CR. Acad. Sci. 294, 1155-1158.

Cano, F., Constantinescu, A., Maitournam, H., 2004. Critere de fatigue polycyclique pour des materiaux anisotropes: application aux monocristaux. Comptes Rendus Mecanique 332 (2), 115-121.

Charkaluk, E., Constantinescu, A., 2009. Dissipative aspects in high cycle fatigue. Mechanics of Materials 41 (5), 483-494.

Chluba, C., Ge, W., de Miranda, R. L., Strobel, J., Kienle, L., Quandt, E., Wuttig, M., 2015. Ultralow-fatigue shape memory alloy films. Science 348 (6238), 1004-1007.

Constantinescu, A., Dang Van, K., Charkaluk, E., 2003. A unified approach for high and low cycle fatigue based on shakedown concepts. Fatigue Fract. Eng. Mater. Struct. 26, 561-568.

Creuziger, A., Bartol, L., Gall, K., Crone, W., 2008. Fracture in single crystal NiTi. Journal of the Mechanics and Physics of Solids 56, 2896-2905.

Dang Van, K., 1973. Sur la résistance á la fatigue des métaux. Sciences Technique Armement 47 (3), $\mathrm{x}-\mathrm{x}$.

Dang Van, K., 1999. High-cycle metal fatigue in the context of mechanical design. 
In: Van, K., Papadopoulos, I. (Eds.), CISM Courses and Lectures no 392. SpringerVerlag, pp. 57-88.

Dang Van, K., Griveau, B., Message, O., 1989. On a New Multiaxial Fatigue Limit Criterion: Theory and Application. In: Brown, M., Miller, K. (Eds.), Biaxial and Multiaxial Fatigue (EGF 3). Mechanical Engineering Publications, London, pp. 479-496.

Doudard, C., Calloch, S., Hild, F., Cugy, P., Galtier, A., 2004. Identification of the scatter in high cycle fatigue from temperature measurements. C.R. Mecanique 332, 795-801.

Doudard, C., Poncelet, M., Calloch, S., Boue, C., Hild, F., Galtier, A., 2007. Determination of an hcf criterion by thermal measurements under biaxial cyclic loading. International Journal of Fatigue 29, 748-757.

Fares, Y., Chaussumier, M., Daidie, A., Guillot, J., 2006. Determining the life cycle of bolts using a local approach and the dang van criterion. Fatigue \& Fracture of Engineering Materials \& Structures 29 (8), 588-596.

Feng, X., Sun, Q., 2007. Shakedown analysis of shape memory alloy structures. International Journal of Plasticity 23, 183-206.

Ferjani, M., Averbuch, D., Constantinescu, A., 2011a. A computational approach for the fatigue design of threaded connections. Int. J. Fatigue 33, 610-623.

Ferjani, M., Averbuch, D., Constantinescu, A., 2011b. Semianalytical solution for the stress distribution in notched tubes. Int. J. Fatigue 33 (4), 557-567.

Frémond, M., 2002. Non-smooth Thermomechanics. Springer-Verlag, Berlin.

Gall, K., Tyber, J., Wilkesanders, G., Robertson, S., Ritchie, R., Maier, H., 2008. Effect of microstructure on the fatigue of hot-rolled and cold-drawn NiTi shape memory alloys. Materials Science \& Engineering, A 486, 389-403.

Gloanec, A.-L., Cerracchio, P., Reynier, B., Van Herpen, A., Riberty, P., 2010. Fatigue crack initiation and propagation of a TiNi shape memory alloy. Scripta Materialia 62 (10), 786-789.

Guerchais, R., Robert, C., Morel, F., Saintier, N., 2014. Micromechanical study of the loading path effect in high cycle fatigue. International Journal of Fatigue 59, 64-75. 
Gupta, S., Pelton, A., Weaver, J., Gong, X., Nagaraja, S., 2014. High compressive pre-strains reduce the bending fatigue life of nitinol wire. Journal of the Mechanical Behavior of Biomedical Materials.

Halphen, B., Nguyen, Q., 1975. Sur les materiaux standards generalises. J. Mecanique $14,1-37$.

Hartl, D., Chemisky, Y., Meraghni, F., 2014. Three-dimensional constitutive model considering transformation-induced damage and resulting fatigue failure in shape memory alloys. In: Proc. SPIE 9058, Behavior and Mechanics of Multifunctional Materials and Composites 2014, 905805.

Hibbert, B., O’Brien, E., 2011. Coronary stent fracture. Canadian Medical Association Journal 183 (11), E756.

Hofmann, F., Bertolino, G., Constantinescu, A., Ferjani, M., 2009. Numerical exploration of the dang van high cycle fatigue criterion: application to gradient effects. Journal of Mechanics of Materials and Structures 4 (2), 293-308.

James, R. D., 2015. Taming the temperamental metal transformation. Science 348 (6238), 968-969.

Jani, J., Leary, M., Subic, A., Gibson, M., 2014. A review of shape memory alloy research, applications and opportunities. Mater. Design 56, 1078-1113.

Kang, G., Kan, Q., Yu, C., Song, D., Liu, Y., 2012. Whole-life transformation ratchetting and fatigue of super-elastic NiTi Alloy under uniaxial stress-controlled cyclic loading. Mater. Sci. Eng. A 535 (0), 228-234.

Karhu, M., Lindroos, T., 2010. Long-term behaviour of binary Ti49.7Ni (at.\%) SMA actuators - the fatigue lives and evolution of strains on thermal cycling. Smart Materials and Structures 19 (11), 115019.

Kim, K., Daly, S., 2011. Martensite strain memory in the shape memory alloy NickelTitanium under mechanical cycling. Experimental Mechanics 51 (4), 641-652.

Koiter, W., 1960. General problems for elastic solids. Prog. Solid Mech.

Lackmann, J., Niendorf, T., Maxisch, M., Grundmeier, G., Maier, H., 2011. Highresolution in-situ characterization of the surface evolution of a polycrystalline NiTi 
SMA-alloy under pseudoelastic deformation. Materials Characterization 62 (3), 298-303.

Lagoudas, D., 2008. Shape Memory Alloys: Modeling and Engineering Applications. Springer.

Lagoudas, D. C., Hartl, D., Chemisky, Y., Machado, L., Popov, P., 2012. Constitutive model for the numerical analysis of phase transformation in polycrystalline shape memory alloys. Int. J. Plasticity 32-33, 155-183.

Leclercq, S., Lexcellent, C., 1996. A general macroscopic description of the thermomechanical behavior of shape memory alloys. Journal of the Mechanics and Physics of Solids 44, 953-980.

Lin, T., 1957. Analysis of elastic and plastic straines of a FCC crystal. J. Mech. Phys. Solids 5, 143.

Luong, M. P., 1998. Fatigue limit evaluation of metals using an infrared thermographic technique. Mechanics of materials 28 (1), 155-163.

Mahtabi, M., Shamsaei, N., Mitchell, M., 2015. Fatigue of nitinol:the state-of-the-art and ongoingchallenges. Journal of the Mechanical Behavior of Biomedical Materials $50,228-254$.

Maitournam, M., Krebs, C., Galtier, A., 2011. A multiscale fatigue life model for complex cyclic multiaxial loading. International Journal of Fatigue 33 (2), 232-240.

Maletta, C., Sgambitterra, E., Furgiuele, F., Casati, R.and Tuissi, A., 2012. Fatigue of pseudoelastic NiTi within the stress-induced transformation regime: a modified Coffin-Manson approach. Smart Mater. Struct. 21 (11), 1-7.

Menna, C., Auricchio, F., Asprone, D., 2015. Chapter 13 - applications of shape memory alloys in structural engineering. In: Concilio, L., Lecce, A. (Eds.), Shape Memory Alloy Engineering. Butterworth-Heinemann, Boston, pp. 369 - 403.

Mertmann, M., Vergani, G., 2008. Design and application of shape memory actuators. The European Physical Journal Special Topics 158, 221-230.

Merzouki, T., Collard, C., Bourgeois, N., Ben Zineb, T., Meraghni, F., 2010. Coupling between measured kinematic fields and multicrystal SMA finite element calcula- 
tions. Mechanics of Materials 42 (1), 72-95.

Morel, F., 2000a. A critical plane approach for life prediction of high cycle fatigue under multiaxial variable amplitude loading. International Journal of Fatigue 22 (2), $101-119$.

Morel, F., 2000b. A critical plane approach for life prediction of high cycle fatigue under multiaxial variable amplitude loading. International Journal of Fatigue 22, $101-119$.

Morin, C., Moumni, Z., Zaki, W., 2010. Cyclic behavior and fatigue design of shape memory alloy devices. In: Proceedings of Plasticity 2010.

Moumni, Z., Van Herpen, A., Riberty, P., 2005. Fatigue analysis of shape memory alloys: energy approach. Smart Mater. Struct. 14, 287-292.

Moumni, Z., Zaki, W., Maitournam, H., 2009. Cyclic behaviour and energy approach of the fatigue of Shape Memory Alloys. J. Mech. Mater. Struct. 4 (2), 395-411.

Moumni, Z., Zaki, W., Nguyen, Q., 2008. Theoretical and numerical modeling of solidsolid phase change: Application to the description of the thermomechanical behavior of shape memory alloys. Int. J. Plasticity 24, 614-645.

Nguyen, Q.-S., 2003. On shakedown analysis in hardening plasticity. Journal of the Mechanics and Physics of Solids 51, 101-125.

Ono, N., Sato, A., 1988. Plastic deformation governed by the stress-induced martensitic transformation in polycrystals. Trans. Jpn. Inst. Met. 29, 267-273.

Papadopoulos, I., 1987. Fatigue polycyclique des métaux: une nouvelle approche. Ph.D. thesis, Ecole des Ponts et Chaussées, France.

Papadopoulos, I. V., 2001. Long life fatigue under multiaxial loading. Int. J. Fatigue 23 (10), 839-849.

Peigney, M., 2009. A non-convex lower bound on the effective energy of polycrystalline shape memory alloys. Journal of the Mechanics and Physics of Solids 57, 970-986.

Peigney, M., 2010. Shakedown theorems and asymptotic behaviour of solids in nonsmooth mechanics. European Journal of Mechanics - A/Solids 29 (5), 784-793. 
Peigney, M., 2013. Shakedown theorems and asymptotic behaviour of solids in nonsmooth mechanics. In: Proc. of EUROMECH 2013 - Colloquium 548 - Direct and variational methods for nonsmooth problems in mechanics. Amboise, France.

Peigney, M., 2014. On shakedown of shape memory alloys structures. Annals of Solid and Structural Mechanics 6 (1-2), 17-28.

Pelton, A., 2011. Nitinol Fatigue: A Review of Microstructures and Mechanisms. J. Mater. Eng. Perform. 20 (4-5), 613-617.

Pelton, A., Fino-Decker, J., Vien, L., Bonsignore, C., Saffari, P., Launey, M., Mitchell, M., 2013. Rotary-bending fatigue characteristics of medical-grade Nitinol wire. J. Mech. Behav. Biomed. Mater. 1, 19-32.

Pelton, A., Gong, X., Duerig, T., 2003. Fatigue testing of diamond-shaped specimens. In: Medical Device Materials, Proc. Materials and the Processes for Medical Devices Conf. pp. 199-204.

Pelton, A., Schroeder, V., Mitchell, M., Gong, X.-Y., Barney, M., Robertson, S., 2008. Fatigue and durability of Nitinol stents. J. Mech. Behav. Biomed. 1, 153-164.

Petrini, L., Migliavacca, F., 2011. Biomedical Applications of Shape Memory Alloys. J. Metall. 2011, 1-15.

Pham, D., 2008. On shakedown theory for elasticeplastic materials and extensions. J. Mech. Phys. Solids 56, 1905-1915.

Poncelet, M., Doudard, C., Calloch, S., Weber, B., Hild, F., 2010. Probabilistic multiscale models and measurements of self-heating under multiaxial high cycle fatigue. Journal of the Mechanics and Physics of Solids 58 (4), 578-593.

Predki, W., Klönne, M., Knopik, A., 2006. Cyclic torsional loading of pseudoelastic NiTi shape memory alloys: Damping and fatigue failure. Mater. Sci. Eng. A 417 (12), 182-189.

Rahim, M., Frenzel, J., Frotscher, M., Heuwer, B., Hiebeler, J., Eggeler, G., 2013. Bending rotation HCF testing of pseudoelastic Ni-Ti shape memory alloys. Materialwissenschaft und Werkstofftechnik 44 (7), 633-640.

Robertson, S., Pelton, A., Ritchie, R., 2012. Mechanical fatigue and fracture of Nitinol. 
Int. Mater. Rev. 57 (1), 1-37.

Runciman, A., Xu, D., Pelton, A., R.O., R., 2011. An equivalent strain/Coffin-Manson approach to multiaxial fatigue and life prediction in superelastic Nitinol medical devices. Biomaterials 32, 4987-4993.

Schijve, J., 2009. Fatigue of Structures and Materials. Netherlands, Springer Science \& Business Media, B.V.

Sedlák, P., Frost, M., Benešová, B., Ben Zineb, T., Šittner, P., 2012. Thermomechanical model for NiTi-based shape memory alloys including R-phase and material anisotropy under multi-axial loadings. Int. J. Plasticity 39, 132-151.

Souza, A., Mamiya, E., Zouain, N., 1998a. A new three-dimensional constitutive model for shape memory alloys. In: Idelsohn, S., Onate, E., Dvorkin, E. (Eds.), Computational Mechanics, New Trends and Applications (CIMNE). Barcelona, Spain.

Souza, A., Mamiya, E., Zouain, N., 1998b. Three-dimensional model for solids undergoing stress-induced phase transformations. Eur. J. Mech. A-Solid 17, 789-806.

Strittmatter, J., Gümpel, P., 2011. Long-time stability of ni-ti-shape memory alloys for automotive safety systems. Journal of Materials Engineering and Performance 20 (4-5), 506-510.

Stupkiewicz, S., Petryk, H., 2012. A robust model of pseudoelasticity in shape memory alloys. Int. J. Numer. Methods Eng. 93 (7), 747-769.

Tabanli, R., Simha, N., Berg, B., 1999. Mean stress effects on fatigue of NiTi. Mater. Sci. Eng. A 644 (8), 273-275.

Tabanli, R., Simha, N., Berg, B., 2001. Mean strain effects on the fatigue properties of superelastic NiTi. Metall. Mater. Trans. A 32, 1866-9.

Taylor, G., 1938. Plastic strain in metals. J. Inst. Met. 62, 307-324.

Treadway, J., Abolmaali, A., Lu, F., Aswath, P., 2015. Tensile and fatigue behavior of superelastic shape memory rods. Materials \& Design 86, 105 - 113.

Tütüncü, R. H., Toh, K. C., Todd, M. J., 2003. Solving semidefinite-quadratic-linear programs using SDPT3. Math. Program. 95 (2), 189-217.

US Food, Drug Administration, April 18th 2010. Non-clinical engineering tests and 
recommended labeling for intravascular stents and associated delivery systems: guidance for industry and FDA staff. US Department of Health and Human Services; Food and Drug Administration, Centre for Devices and Radiological, Health.

Van, K. D., Maitournam, M., 2002. On some recent trends in modelling of contact fatigue and wear in rail. Wear 253 (1), 219-227.

Wackers, P., Alquezar-Getan, M., Constantinescu, A., Maitournam, H., Arrieta, V., 2010a. A Modeling Approach to Predict Fretting Fatigue on Highly Loaded Blade Roots. J. Eng. Gas Turbines Power 132 (8), 1-9.

Wackers, P., Arrieta, V., Alquezar-Getan, M., Constantinescu, A., Maitournam, H., 2010b. A modeling approach to predict fretting fatigue on highly loaded blade roots. Journal of Engineering for Gas Turbines and Power 132 (8), 082101.

Wang, X., Xu, B., Yue, Z., 2008. Phase transformation behavior of pseudoelastic NiTi shape memory alloys under large strain. J. Alloys Compd. 463 (1172), 417-422.

Wu, X., Grummon, D., Pence, T., 1999. Modeling phase fraction shakedown during thermomechanical cycling of shape memory materials. Mater. Sci. Eng. A 273-275, $245-250$.

Yin, H., He, Y., Sun, Q., 2014. Effect of deformation frequency on temperature and stress oscillations in cyclic phase transition of NiTi shape memory alloy. Journal of the Mechanics and Physics of Solids 67, 100-128.

Zaki, W., Moumni, Z., 2007. A 3D model of the cyclic thermomechanical behavior of shape memory alloys. Journal of the Mechanics and Physics of Solids 55, $2427-$ 2454.

Zaoui, A., 1987. Taylor-type modelling of polycrystal plasticity. In: Sanchez-Palencia, E., Zaoui, A. (Eds.), Homogenization Techniques for Composite Media. Vol. 272 of Lecture Notes in Physics. Springer Berlin Heidelberg, pp. 350-359.

URL http://dx.doi.org/10.1007/3-540-17616-029 